\title{
Adverse Selection and Repeated Insurance Contracts : Reply
}

\author{
by Georges Dionne*
}

In his comment J. Hofmann [1983] mentioned that the " no claim discount strategy " presented in Dionne [1983] does not eliminate inefficiency at all because "it is not possible to motivate the insured to declare the true class of risk without cost. The costs of motivating the insured to declare the true risk are the costs of uncertainty to be punished ". Moreover the author said that there is another secondary risk situation: "Since the insured is risk-averse, a constant premium is preferable to a variable premium".

In this reply I will argue that the comment of J. Hofmann is not correct when the number of periods is infinite but has to be considered when the number of periods is finite.

In the paper published in this journal [Dionne, 1983] I have shown that, using the Law of Iterated Logarithm, it is possible to obtain "full efficiency allocation of risks that is the insurer is now able to enforce the consumer to announce the true class of risk he belongs and to sell full insurance coverage to all individuals regardless of their class of risk" p. 326. This

\footnotetext{
* University of Montreal.
} 
result is proved for a infinite number of periods (see Theorem I and its proof) and is true because the statistical tool used prevents the insurer from penalysing too often those who tell the truth and permits him to find rapidly enough those who cheat. " If an insured tells the truth he will be penalized only finitely many times with probability one" (p. 326). Then, in an infinite horizon model, there is no cost for the consumer to be penalyzed finitely many times and the comment of Dr. Hofmann does not apply in this type of model.

However when the number of periods is finite, the types of risk mentioned by Dr. Hofmann have to be considered. In an extension of the paper published in this journal, Dionne and Lasserre [1983] have shown that, when the number of periods is finite, only second best solutions can be obtained.

\section{REFERENCES}

DIONNE, G. [1983] : "Adverse Selection and Repeated Insurance Contracts", The Geneva Papers on Risk and Insurance, 8, No. 29, October 1983), pp. 316-332.

DIONNE, G., LASSERRE, P. [1983] : “Adverse Selection and Repeated Insurance Contracts : Finite and Infinite Horizons", Working Paper No. 8326, Department of Economics, Université de Montréal.

HOFMANN, J. [1984] : “Adverse Selection and Repeated Insurance Contracts : a Comment ". This issue of the Geneva Papers on Risk and Insurance. 